\title{
EL AGUIJÓN DE ARISTÓFANES Y LA MORALIDAD DE LOS JUECES*
}

\author{
Guillermo Lariguet \\ Conicet, IDH, UNC, Argentina
}

RESUMEN. En este trabajo utilizo la literatura como fuente de reflexión filosófica. En efecto, partiendo de la obra Las avispas de ARISTÓFANES realizo un análisis filosófico de la importancia que tiene la moralidad de los jueces en la aplicación del derecho a casos concretos. Sostengo que la ética de la virtud puede ser una corriente que complemente las versiones deontologistas y consecuencialistas que durante mucho tiempo han dominado la ética judicial. Asimismo, cuestiono la validez teórica del positivismo metodológico para dar cuenta adecuadamente del tipo de conexión fuerte que existe entre moralidad y derecho. Expongo el modo en que la frónesis o prudencia interviene en la aplicación del derecho a casos particulares.

Palabras clave: literatura, virtudes judiciales, vicios, moralidad, positivismo metodológico, prudencia.

\section{Aristophanes' Sting and the Morality of Judges}

ABSTRACT. In this work I use literature as a source of philosophical reflection. Indeed, I base my research on the play by ARISTOPHANES «Wasps» doing a philosophical analysis of the importance of morality of judges in applying the law to specific cases. I argue that virtue ethics can be a complement to current deontologists and consequentialist versions that have long dominated judicial ethics. Also, I question the theoretical validity of methodological positivism to account adequately the type of strong connection between morality and law. In addition, I show the way in which phronesis or prudence intervenes in the application of law to particular cases. dence.

Keywords: literature, judicial virtues, vices, morality, methodological positivism, pru-

* Fecha de recepción: 23 de julio de 2013. Fecha de aceptación: 20 de septiembre de 2013.

Estoy agradecido con los dos árbitros anónimos por sus sugerencias destinadas a mejorar el trabajo. Al mismo tiempo, agradezco a A. AMAYA y a P. GAIDO por sus detalladas observaciones que me ayudaron a mejorar versiones previas a este texto. 
La manera más familiar que hay en la ética de acudir a la ficción reposa sobre la idea de que los mundos ficticios pueden proporcionar a la ética experimentos de pensamiento. Doy por sentado que ésta es una versión de la idea tradicional de que la ficción puede proveer exempla saludables de virtud y vicio, B. WILLIAMS, «Las traquinias: ficciones, pesimismo, ética. El sentido del pasado, Traducción de Adolfo García de la Sienra», 2012, 83.

\section{INTRODUCCIÓN}

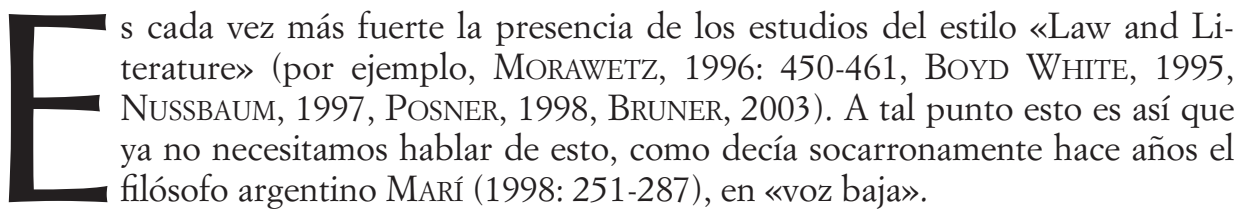

Estos estudios han argumentado de manera convincente sobre la relevancia de la literatura para el derecho en un triple sentido. En primer lugar en lo que se conoce como el derecho de la literatura, en segundo lugar el derecho en la literatura y por último con relación al derecho como literatura (Ost, 2006: 334; AMAYA, 2012: 3). De estos tres sentidos, este trabajo estará gobernado por el segundo sentido: el derecho en la literatura.

El derecho aparece retratado en la literatura desde antiguo (MAGRIS, 2008; ANDERSON CAMACHO, 2007: 67-85). Si sólo pensamos en occidente, veremos que la presencia del derecho, la justicia, el poder o el estado aparecen en obras trágicas griegas como la Antígona de SÓFOCLES o las Euménides de ESQUILO. Como ha afirmado ARISTÓTELES el género trágico trata de la caída de gente noble, gente buena que se ve forzada a hacer o soportar cosas malas. Dado que en otros trabajos (LARIGUET, 2008; LARIGUET y MARTíNEZ, 2008; LARIGUET, 2011) he explorado el vínculo entre el género trágico y el derecho, en este artículo quisiera centrarme en su opuesto: la comedia; concretamente en la comedia ática y, más específicamente, en la comedia desarrollada por ARISTÓFANES (véase SILK, 2001).

La comedia, como también ha sostenido el filósofo de Estagira, se dirige a mostrar, a diferencia de la tragedia, caracteres morales ruinosos o deplorables, buscando explotar los aspectos risibles de los mismos ${ }^{1}$. En este trabajo voy a basar principalmente mi análisis — que será de tipo filosófico- en la comedia Las avispas, porque la misma encarna una caricaturesca visión de los jueces y su modo de aplicar el derecho de aquella época (SCAFURO, 1997). Sostendré que a través de Las avispas (ARISTÓFANES, 2011a), podemos extraer el «aguijón de ARISTÓFANES», aguijón que nos estimula a meditar sobre las condiciones bajo las cuales puede ser moral la labor judicial. Cabe aclarar que, ocasionalmente, para reforzar mi presentación de algunos puntos clave del trabajo vinculados a la justicia, apelaré a Las nubes ${ }^{2}$ (ARISTÓFANES, 2011b), obra en la que el

1 Como acertadamente señala uno de los árbitros de este trabajo, la comedia era un género no carente de «virtualidad» didáctica y política; castigat ridendo mores (Satyra quae ridendo corrigit mores), del que corrige o enmienda las costumbres mediante la ridiculización humorística de ciertos comportamientos viciosos.

2 Una obra importante es Las aves, también traducida como Los pájaros. En esta obra igualmente se critica la labor de los jueces y la energía ateniense puesta en la multiplicación del litigio (BuIs, 2001: 7-22). Sin embargo, la crítica más profunda en las Aves va dirigida a la democracia ateniense y su vínculo con la sofística. Por esta razón, no la abordaré aquí sino en un trabajo independiente que explore el papel de los jueces en una democracia. 
comediógrafo griego se mofa de los sofistas y su peculiar manera de torcer argumentos para defender causas injustas.

Una primera cuestión que puede surgir para un trabajo como el que propondré es la siguiente: ¿Qué relevancia puede tener mirar hacia un pasado remoto como el de la democracia radical representada por Cleón; democracia de la que se burla ARISTÓFANES? ¿Qué nos puede enseñar un tiempo pretérito, o una pieza de museo, sobre el presente de nuestros ordenamientos constitucionales contemporáneos? En este ensayo participo de la idea de que la historia, entendida como el depósito de sentido del presente, puede contribuir a iluminar nuestros problemas actuales si lo comparamos con el tipo de controversias que se presentaban en el pasado. La historia no es un dique cuyo cauce se corta. Por el contrario, sus aguas fluyen y las capas diversas de la historia pueden ser reexaminadas una y otra vez para comprender la naturaleza actual de nuestros problemas. Justamente B. WiLLIAMS (2011: 202-221; 2012) ha sostenido que la filosofía como disciplina bumanística debe aprovecharse del carácter histórico de nuestros conceptos, en una vena muy similar a la que NIETZSCHE defendía cuando mostraba las bondades de una investigación de tipo genealógico.

Ajustando más aun cuáles son los objetivos de este trabajo diré que me interesa analizar filosóficamente el modo en que la cuestión de la moralidad de los jueces puede ser repensada a partir de las ironías deslizadas por ARISTÓFANES en las obras antes citadas $^{3}$. ARISTÓFANES no está solo en la empresa de cuestionar la moralidad de jueces o abogados con el recurso a la mofa o la burla. Siglos más tarde, ANDERSEN, en el cuento El traje del emperador, revelará la manera en que un carácter altanero y vanidoso puede ser un obstáculo cognitivo en el desempeño del poder público. Por su parte, En los viajes de Gulliver, Swift, por boca del capitán Gulliver, objetará la manera en que los abogados se las apañan para tender en sus argumentos, lo que la filósofa española M. BORDES SOlANAS ha llamado «las trampas de Circe» (2011), es decir, celadas o trampas argumentales que sólo buscan persuadir al costo de la validez o solidez de los argumentos, tal como siglos antes estilaban los sofistas ridiculizados por ARISTÓFANES en Las nubes.

Para cumplir con el objetivo propuesto estructuraré este trabajo del siguiente modo. En primer lugar, presentaré fragmentos de Las avispas, reforzados ocasionalmente con fragmentos de Las nubes, para indicar las vías que escoge el comediógrafo griego para poner en cuestión la moralidad de los jueces atenienses (sección 2). En segundo lugar, esbozaré la manera en que se puede entender la idea de que no sólo nos importa la aplicación técnica de las reglas, sino también establecer cuál es el carácter moral de los jueces que las aplican (sección 3). En la última parte (sección 4), defenderé que un enfoque adecuado para dar cuenta de la moralidad de jueces o abogados puede ser reconstruido con provecho si utilizamos los aportes de la ética de la virtud y, en vez de hablar sólo de deberes judiciales, hablamos también de virtudes judiciales. De manera paralela (subsección 4.1), argumentaré sobre la inadecuación del positivismo metodológico para captar la relación fuerte que existe entre moralidad y derecho. Esta relación la entiendo como mediada por nuestra expectativa normativa de que los

3 Debo aclarar que mi acercamiento a ARISTÓFANES no está motivado por un deseo de reconstrucción filológica. Repasaré párrafos de Las avispas con el fin de tener un trampolín para el análisis conceptual. Quizás esto me ponga ante un inevitable cultismo de la obra de ARISTÓFANES. 
jueces deben ser no sólo técnicamente competentes sino también virtuosos. Luego (subsección 4.2) completaré mi análisis conceptual con la invocación de la frónesis como una virtud característica y sintética de jueces virtuosos. Por último, (sección 5) repasaré los hitos principales del trabajo.

\section{EL AGUIJÓN DE ARISTÓFANES}

Si SóCRATES fue conocido como el «tábano» de Atenas por sus afiladas preguntas a los eruditos de su época, ARISTÓFANES, con el recurso a un humor mordaz, fue el «aguijón» de los griegos. Aquí voy a centrarme principalmente en Las avispas y, cuando sea necesario para reforzar una idea puntual, acudiré también a Las nubes.

El contexto político de Atenas es el de la democracia radical liderada por Cleón. Los jueces, a los que ARISTÓFANES apodará como las «avispas», son generalmente, aunque no en exclusivo, ancianos que pelearon distintas guerras contra los persas. A modo de recompensa y de jubilación, el estado griego les paga un sueldo magro que apenas les alcanzaba para satisfacer sus necesidades más básicas.

Los principales protagonistas de Las avispas son Filocleón (el que ama a Cleón) y su hijo Bdelicleón (el que odia a Cleón). La corrupción es el principal problema moral y político que denuncia ARISTÓFANES a través del humor. Esta corrupción es explicada por la injerencia del poder político en el poder judicial. Aunque todavía en la Grecia de ARISTÓFANES no existía lo que hoy conocemos como independencia de los poderes y el sistema «check and balance», sí que existía ya una cierta idea rudimentaria de que tales poderes debían ser independientes entre sí. El jefe de gobierno, Cleón, principal objeto de las críticas del literato griego, utilizaba a los jueces para perseguir a sus adversarios políticos, «fabricándoles» causas que principalmente tenían que ver con denuncias de malversación de fondos públicos o defraudación al Estado. De este modo, los jueces eran instrumento del poder político para la persecución de lo que, siglos después, Schmitt llamaría los «enemigos» del gobierno. Bdelicleón será el personaje que intentará torcer la visión aduladora y cómplice hacia el poder político de su padre Filocleón.

La falta de independencia, así como de imparcialidad y objetividad de los jueces, es al principio del texto denunciada por un sirviente (Sosias) de Filocleón que narra que tuvo un sueño en el que le pareció que un «rebaño sentado sesionaba en asamblea...». Luego, continua, «me pareció que a estos corderos les pronunciaba discursos una ballena voraz con la voz de una cerda enfurecida» (45). Mientras la metáfora del «rebaño» alude a los jueces, la imagen de una «ballena voraz» refiere a Cleón que se comporta como una «cerda enfurecida», es decir, con «cólera».

Otro sirviente, Jantias, sostiene que a su amo —es decir a Filocleón- le acosa una enfermedad muy particular que no son ni los dados ni la bebida, sino su «afición a ser juez» (50). El juez Filocleón, además, tiene un rasgo problemático de carácter. Esto consiste, según Jantias, en que su «mal carácter lo hace aplicar siempre la pena máxima» (52). Más adelante, el propio Filocleón se describe a sí mismo diciendo «yo soy el humo» (55).

El humo, como explican los filólogos, significaba para los griegos la apelación metafórica a la soberbia o fanfarronería y a la inestabilidad del carácter. Ante esta 
auto-descripción, su hijo Bdelicleón, replica que sin duda es el «más acre» de los humos; pues, ARISTÓFANES, frecuentemente tildaba a los jueces de «duros, ásperos o acres». Más tarde, el mismo Bdelicleón dirá, al referirse a la casta judicial que, «si es irritada, la estirpe de los viejos, es igual a un avispero. Del lomo les sale un aguijón afilado, con el cual pican, y zumban, y saltan y tiran como chispazos» (63). Este aguijón es especialmente utilizado contra los adversarios de Cleón. Por ejemplo, Laques, renombrado militar, recordado a su vez en uno de los diálogos platónicos, será uno de los perseguidos por los jueces adictos a Cleón. Los propios jueces, a propósito de esto, dirán que «ayer Cleón, nuestro protector, dio orden de que puntuales llegáramos con provisiones para tres días... de cólera terrible» para castigarlo por sus injusticias (66).

Nuevamente, como se puede advertir, la pasión de la «cólera» es la que motiva la acción de los ancianos jueces. Pero el castigo por las injusticias no sólo se apoya en la cólera. También en las «artimañas» de una argumentación de tipo sofista empleada para justificar sentencias inicuas o razonamientos tendenciosos. Precisamente éste es el punto que ARISTÓFANES aborda en su comedia Las nubes. En la misma, Estrepsíades, un personaje que debe dinero a muchos acreedores, quiere ingresar a la academia de Sócrates con el fin de aprender las argucias del razonamiento para convencer a sus acreedores de que no está en realidad obligado a pagarles. La apelación a Sócrates es sin duda injusta pues el maestro de la mayéutica, como sabemos, combatió repetidamente a los sofistas. Más aún, en el Gorgias, Platón sostendrá que el razonamiento lógicamente válido y sólido no está separado del carácter virtuoso del razonador. No hay hiato en la ética platónica entre ser un buen argumentador y ser una buena persona. Pero, más allá de ello, lo que quiero enfatizar, a través de la cita de Las nubes, es que era común que los jueces emplearan la doctrina sofista para persuadir —mediante estratagemas falaces- sobre el resultado que querían lograr ${ }^{4}$. Para ARISTÓFANES, los jueces, al igual que los sofistas de las nubes, zumban no con la trompa sino por el «trasero» como los mosquitos (42). Por ello, «quien conoce el intestino de un mosquito» es capaz de ganar cualquier causa, especialmente las malas o injustas.

La analogía entre el razonamiento falaz o sofístico, motivado por el interés en que triunfe la injusticia, por un lado, y el «trasero» de un mosquito, apuntan justamente a plantear cuán «sucio» es el ejercicio forense del derecho (sobre el funcionamiento de la judicatura y el papel de la argumentación véase BONNER y SCHMITT, 2000). Además, se trata de un ejercicio amañado. La imagen del estrecho intestino de un mosquito se potencia con la idea según la cual la argumentación es usada para «discutir sobre sutilezas, hablar de humo, y contradecir argumentos con argumentos» (51). El tipo de argumentación que ridiculiza ARISTÓFANES, no es aquel orientado por razones plausibles, o cincelado por pasiones con capacidad para motivar acciones morales o justas. Se trata de una argumentación que usa las sutilezas, el humo y la argumentación para confundir. Al vicio del humo, «característico de la soberbia», se le agregan otros que el propio Estrepsíades, en Las nubes, admite que puede adquirir una vez que logre la «elocuencia» en las palabras. Lo único que a este personaje le interesa es dejar de pagar sus deudas. Si lo logra, no le importa que «pase por hombre atrevido, charlatán, teme-

4 Un ejemplo magistral en la literatura de un proceder que apela a las formas del razonamiento para defender tesis sustantivas implausibles es el memorable Banquero Anarquista de F. PESSOA. 
rario, sinvergüenza, costal de mentiras, inventor de frases, trillado en los pleitos, litigante perpetuo, molino de palabras, zorro astuto, penetrante barreno, correa flexible, disimulado, escurridizo, fanfarrón, insensible como el nudo de las maderas, impuro, veleta y parásito imprudente» (59).

Una de las características de estos jueces sobre la que insiste una y otra vez ARISTÓFANES en Las avispas es su falta de sensibilidad para los contra argumentos; por esto los compara con la dureza de las piedras (68). Estos jueces, que ya estaban decididos a condenar a cualquier perseguido por Cleón, son los que están muy dispuestos a ir a las urnas para hacer «daño» $(73)^{5}$.

Frente a este cuadro moral, Bdelicleón le dice a su padre «llénate de discursos. Un día acabará todo esto y parecerás un culo al que no haya baño que lo limpie, después de tanta ostentación de poder» (101).

Los jueces, sin embargo, tienen tal poder que no dudan compararse con los mismos dioses; por esto el mismo Filocleón dirá que su poder en nada difiere del de Zeus (102) porque, continúa Filocleón, «cuando relampagueo, chasquean los labios y se cagan encima los ricos y también la gente más importante» (103). Estos jueces, temidos por los ciudadanos, están prestos siempre a dar «mordiscos» (118) a los que tienen que defenderse en un proceso judicial. Bdelicleón, que está muy ocupado en convencer a su padre de la necesidad de cambiar de actitud moral, desea en un momento, refiriéndose a su padre, «que desde ahora sea compasivo con los hombres, más con los acusados que con los acusadores, y que llore ante los que le imploran, y acabe con ese mal carácter y de su ira arranque las ortigas» (129). Por el contrario, cuando los jueces optan en la obra por describirse a sí mismos sostienen que «si nos observáis con atención en muchos aspectos, encontraréis que en todo sentido, en el carácter y en el modo de vida nos asemejamos mucho a las avispas. En primer lugar, ningún animal, cuando es provocado, es más irascible ni más intratable que nosotros. Y, luego en todo lo demás, nos manejamos del mismo modo que las avispas. Nos agrupamos en enjambres como en los avisperos» (129). Esta cita, muestra, una vez más, los rasgos sobresalientes de carácter de los jueces-avispas. Jueces que, además, se comportan como una «corporación cerrada», pues se agrupan en enjambres como las avispas.

Todo lo dicho hasta ahora, muestra cómo opera el insistente «aguijón» de ARISTÓFANES. El mismo opera en dos niveles. Por una parte en el nivel de los jueces-avispas que están dispuestos a picar condenatoriamente a los procesados como los insectos a sus víctimas humanas. Los jueces-avispa son imprudentes, veletas, iracundos, soberbios, feroces, etc. Por la otra parte, en una suerte de «meta-nivel», está el propio

5 Me parece pertinente citar textualmente el comentario de uno de mis árbitros cuando, sobre la naturaleza de la labor judicial ateniense criticada por ARISTÓFANES, señala lo siguiente: «La principal reflexión a que ellos —o sea, la labor de los jueces_ invitan no me parece intrascendente en el tema que el autor aborda. Los jueces eran designados por el poder político, ciertamente, pero la estrategia de control era más amplia porque en Atenas existió un consciente y decidido empeño por obstaculizar en general el desarrollo de las profesiones jurídicas ligadas al proceso. La actuación de jueces poco o nada "virtuosos” era, por tanto, menos problemática en ausencia de abogados defensores, y hasta "fiscales", que carecían de reconocimiento profesional y social dentro y fuera de los tribunales atenienses. Este puede hacer reflexionar sobre el papel de "centinela" de las virtudes judiciales que le cabe cumplir a la abogacía, sin el que los excesos judiciales escapan por vía política o corporativa a toda vigilancia. Las "virtudes" del juez también se leen a través de la labor de oros operadores procesales». 
aguijón de ARISTÓFANES. Su obra Las avispas es un poderoso aguijón sobre las conciencias, buscando, con el expediente del humor, mostrar las fallas en el carácter moral de ciertos jueces. Es tiempo, por ello, de ocuparse a continuación de este tema.

\section{LA MORALIDAD DE LOS JUECES}

Durante mucho tiempo la filosofía del derecho ha estado dominada por dos tipos de paradigmas. Uno de ellos, más de corte formalista, estaba basado en un énfasis en el apego de los jueces al tenor literal de las reglas que debían aplicar puntualmente. El otro, en cambio, estaba fundado en la idea de cómo los jueces podían, mediante su función, maximizar el logro de objetivos colectivos. El primer paradigma es el «deontologismo judicial», mientras que el segundo, el teleologismo o consecuencialismo judicial. Esta división en paradigmas, sin embargo, no es exclusiva del mundo jurídico. En la filosofía moral, parejamente, encontramos una distinción entre un enfoque de tipo kantiano, apegado a las reglas, claramente enraizado en el deontologismo mientras que, por el otro lado, el utilitarismo, primero de los actos, y luego de las reglas, se vincula con un paradigma teleologista o consecuencialista (vid. LARIGUET, 2012). Me atrevería a sostener que estos dos paradigmas, en buena medida, han sido muy influyentes de las dos grandes direcciones que ha adoptado el llamado razonamiento judicial: una de tipo formalista con excesiva reverencia por la aplicación literal de las reglas y otra más política, vinculada a la conexión del razonamiento con el logro, a través de la judicatura, de objetivos políticos colectivos. No obstante, viene ganando territorio, una tercera forma de abordar la naturaleza de la labor judicial y el razonamiento forense. Me refiero a la corriente «aretaica», esto es, aquella que deriva de la idea de «aretai», «excelencias de carácter» que utilizamos para evaluar el temperamento o carácter moral de los jueces (FARRELLY y SOLUM, 2007; ATIENZA, 2001: especialmente cap. VI). La corriente aretaica presupone una reapropiación de la ética de las virtudes, principalmente de linaje aristotélico. Esta corriente se presenta como una genuina teoría normativa (GONZÁLEZ DE LA VEGA, 2013: 76) de la moral basada en la idea de virtudes, en este caso de índole judicial. Conforme este paradigma, el acento está puesto no tanto en la aplicación de las reglas o en la maximización de ciertas consecuencias globales sino en el desarrollo pleno de virtudes de carácter (AmAYA y Ho HocK LAI, 2012). En buena medida las virtudes se pueden caracterizar como disposiciones estables de carácter, que se encuentran armónicamente integradas, y que conducen al agente a desempeñarse de manera moral, respondiendo de manera correcta a los desafíos morales que se le puedan presentar.

En este trabajo quiero sugerir que el enfoque de las virtudes es una manera fértil de plantear el viejo problema de la «moralidad» del derecho. En vez de enfocar esta cuestión clásica con las lentes de la legitimidad, autoridad o normatividad del dere$c h o^{6}$, centradas, por lo general, al nivel sistemático e institucional del derecho, aquí pretendo dirigir la atención hacia otra cuestión. En efecto, creo que es necesario poner el acento en las virtudes de los protagonistas que aplican el derecho, en este caso los jueces. Voy a sostener que el enfoque de las virtudes resulta un complemento teórico

6 Términos que pese a sus diferencias conceptuales aquí me permito usar en forma sinonímica. 
ineludible de aquellas otras categorías (legitimidad, autoridad o normatividad) que acabo de mencionar. La idea es que no se puede hacer una buena filosofía jurídica que dé cuenta de la conexión entre derecho y moral sólo recabando el nivel institucional. Como diré aquí, tenemos expectativas normativas de que los jueces deben ser morales. Por tanto no basta siquiera concentrarse en el momento final de la «acción» de tomar una decisión judicial. Es menester, antes que nada, tener en cuenta el «preámbulo» necesario para tomar buenas decisiones. Me refiero, claro está, a las virtudes que los jueces deben exhibir.

Hace relativamente poco tiempo, A. SEN (2011: 105-116) ha sostenido que las teorías de la justicia, tradicionalmente, han dado mayor preponderancia a las cuestiones del diseño adecuado de «instituciones» y concedido menos atención a la cuestión de las «personas justas». En una línea familiarmente semejante, creo que los enfoques iusfilosóficos tradicionales han discutido la relación entre moral y derecho al nivel «marmóreo» de las instituciones (las reglas que regulan la judicatura, la legislación, etc.) y menos atención al carácter moral de las personas de carne y hueso que integran dichas instituciones. Si el derecho es finalmente normativo, moral o legítimo no es una cuestión que sólo dependa del material institucional, sino también de la cuestión de los rasgos de carácter que deberían satisfacer sus funcionarios.

La presencia, cada vez mayor de los códigos de ética profesional y, más concretamente, de ética judicial (AGUILÓ, 2009: 525-540), sugiere que la cuestión del desempeño moral de los jueces es un tema de suma actualidad y relevancia. Suponiendo que un derecho determinado pudiera ser tildado de inmoral o injusto (por ejemplo el llamado derecho nazi, o el del apartheid), o que cierta ley o regla particular lo sea, ello todavía deja abierta la cuestión de la moralidad o inmoralidad de los jueces. Si, además de un derecho inmoral o injusto, o una ley o regla particular inmoral o injusta, añadimos ahora el ingrediente de jueces inmorales o injustos, el problema se agrava considerablemente. Un juez moral o justo, esto es, un juez «virtuoso», podría quizá tener la chance de enmendar parcialmente la inmoralidad o la injusticia de la mano de una aplicación virtuosa del derecho. Pero si el derecho es inmoral y los jueces también lo son, prácticamente toda esperanza está perdida 7 .

El aguijón de ARISTÓFANES tiene el valor de sacarnos de la burbuja inocente según la cual los jueces, por un extraño malabarismo conceptual son, por definición, morales y justos, es decir, virtuosos. Contra esta versión excelsa de los jueces, la literatura, en concreto una obra como la de ARISTÓFANES, nos ayuda a invertir el espejo y partir de los «vicios». Los jueces de Las avispas son jueces inclementes, soberbios, vanidosos, veletas, inestables, coléricos o iracundos, dependientes del poder de turno y, por ende, parciales en sus juicios. ARISTÓFANES nos muestra, de esta forma, las fallas de carácter que influyen directamente en el contenido injusto e inmoral de ciertas decisiones judiciales.

No hace tanto tiempo M. SALAS incrustó un aguijón todavía más escéptico que el del comediógrafo griego. Según M. SALAS (2007: 581-600) el derecho es una profesión esencialmente inmoral. Quien quiera jugar dentro de este mundo de la vida tendrá

\footnotetext{
7 La hipótesis inversa es qué sucede cuando un derecho es justo pero los jueces son injustos. En estos casos se revela con mayor claridad la necesidad conceptual de que los jueces deben ser virtuosos y dotados de una sensibilidad aguda por la justicia en los casos concretos.
} 
que aceptar que el ejercicio de la justicia está manchado de inmoralidad. M. SALAS no duda, en este sentido, en apoyar su afirmación estableciendo una semejanza entre los jueces y los «recolectores de basura», semejanza que se basa en el hecho de que ambos tipos de personas «huelen mal».

Algo parecido al escepticismo de M. SALAS, o pesimismo si queremos ser más precisos, sostenía Platón en Las Leyes. Contra esta visión tan escéptica que entiende que el derecho está atacado de una (in) moralidad intrínseca, MALEM SEÑA (2001:379-403) ha indicado que el derecho requiere para su estudio el enfoque en la moralidad de los jueces y que, en consecuencia, las «malas personas» no pueden ser — técnicamentebuenos jueces. Sin embargo, cuando MALEM defiende esta tesitura, no acompaña la misma de una clara conceptualización de qué quepa entender por «mala persona». Sus variados ejemplos van desde el juez que viste ropas estrafalarias, o se contonea al compás de la música tropical en una disco, hasta el juez fascista que contraviene valores de un estado constitucional del derecho o el juez que publica imágenes pornográficas en su blog. Mientras algunos ejemplos hablan de la moralidad privada (por ejemplo el juez en la disco) otros apelan a la esfera pública (el juez que adhiere a la doctrina fascista por ejemplo). En ningún momento queda claro qué define a una persona como «mala» y por qué esta constitución moral afecta el desempeño técnico correcto de jueces que, suponemos, conocen bien el derecho. MALEM, al final de su trabajo, se muestra vacilante y parece inclinarse por definir la moralidad de los jueces sólo a partir de los casos donde los valores morales de los jueces son incompatibles con los valores morales de un determinado ordenamiento constitucional. Pero, en otras partes de su texto, MALEM utiliza un criterio diferente al de la armonía con los valores públicamente sancionados en una constitución. En efecto, lo que parece contar como baremo de evaluación moral de la conducta de los jueces no es tanto que estos «sean» morales como que «aparezcan» como tales. En otras palabras, la confianza del justiciable en el derecho parece estar vinculada a la «buena imagen», a la «apariencia» que irradien los jueces. En tal sentido, a diferencia de una genuina moralidad «crítica» y «reflexiva» parece que esperamos de los jueces una suerte de moral «farisea». Después de todo, un juez que fuera auténticamente moral no necesitaría aparentarlo.

Más promisorio, según creo, es el camino trazado, entre otros, por A. AMAYA (2013). Con mayor precisión y claridad, esta filósofa sostiene que los «ejemplares morales» son criterios normativamente confiables para evaluar el comportamiento de los jueces. Los ejemplares morales que según la misma AMAYA, pueden surgir de la jurisprudencia, como de las obras de ficción o literarias, son aquellos que instancian virtudes, es decir, que son «tokens» o «ejemplares» de virtudes morales (como honestidad, magnanimidad, coraje o prudencia), y también de virtudes intelectuales (como apertura mental, perseverancia, autonomía y humildad intelectuales, etc.). En lo que sigue, con el rótulo «virtudes judiciales», tendré en cuenta tanto lo que, por una cuestión más de estilo que de fondo ${ }^{8}$, llamamos virtudes intelectuales y morales que deben integrar el temperamento de los jueces.

${ }^{8}$ Un lugar común en la filosofía occidental ha sido generar algo así como una visión «purificada del intelecto» según la cual el intelecto tiene una maquinaria, un funcionamiento y unos rasgos independientes de los sentimientos y respuestas emocionales. Sin embargo, esta distinción, trasuntada en la independencia aristotélica entre virtudes intelectuales y morales, es sumamente cuestionada en la filosofía actual. Por ejemplo, 


\section{EL ENFOQUE DE LAS VIRTUDES JUDICIALES Y LA FALLA DEL POSITIVISMO JURÍDICO METODOLÓGICO}

Como hemos visto, ARISTÓFANES utiliza un insistente aguijón para hablar de la inmoralidad de los jueces. Esta inmoralidad está enraizada en fallas de carácter, en vicios ya descriptos con apego a la obra citada del comediógrafo griego, que impactan en el dictado de sentencias injustas o inmorales; sentencias que, como dicen los propios jueces-avispas, producen «daño» injustificado. Precisamente, buena parte del núcleo de lo inmoral, como ya lo entrevió con lucidez J. STUART MiLL, tiene que ver con el daño injustificado a terceros.

Precisamente, debido a sus fallas de carácter, los jueces-avispas elaboran sentencias inmorales o injustas. La inmoralidad o injusticia surge de castigar a los inocentes; de condenar por delitos que no cometieron a las personas en general y a los personajes fastidiosos para el poder político de turno en particular. Estos jueces no sólo son coléricos, vanidosos o veletas, son jueces que gustan de la adulación, que se someten a las presiones políticas y que, en consecuencia, sacrifican su independencia y su imparcialidad.

$\mathrm{El}$ argumento en el que voy a insistir tiene las siguientes partes. Premisa 1: Si tomamos en serio que los jueces no pueden aplicar de manera moralmente correcta el derecho si no son virtuosos. Premisa 2: Si, además, aceptamos, por mor de esta línea de trabajo, que los jueces carentes de virtud tenderán a cometer fallas argumentativas cruciales en el momento de la aplicación del derecho a casos concretos. 3. Conclusión: Entonces, parece que debemos decirle adiós al positivismo jurídico concentrado, en todo caso, en las propiedades sistemáticas del derecho pero ciego al papel de las virtudes judiciales en una aplicación y argumentación moralmente impecables del derecho a un caso particular.

Para que se entienda más cabalmente el tipo de descontento teórico que trasunta la premisa 2, dividiré esta sección en dos partes. En la primera, ofreceré algunas notas de porqué el positivismo jurídico metodológico me parece insatisfactorio para dar cuenta de la necesidad de virtudes morales en los jueces. En la segunda, y ya más específicamente, explicitaré el papel de la frónesis o prudencia que, aunque para los aristotélicos es una virtud intelectual aplicada al campo de la praxis, no es menos cierto que la misma no se da de manera divorciada del resto de virtudes morales que, en el caso del objeto del presente estudio, deben poseer los jueces en su desempeño.

\subsection{Las fallas del positivismo jurídico metodológico}

Sinceramente soy de la opinión de que el positivismo jurídico metodológico, esto es, aquel que separa conceptualmente el derecho de la moral, es un fracaso teórico de proyecciones actuales hoy en día fantasmagóricas. Como el padre de Hamlet, esta clase

ZAGZEBSKI (1996: 137 y ss.) ha demostrado cómo en las virtudes intelectuales se dan aspectos emocionales y cómo en las virtudes morales aspectos cognitivos. En consecuencia, la distinción no es conceptualmente fuerte. Esto a su vez se hace patente en el ámbito epistemológico de las «teorías del conocimiento» que también han incorporado el lenguaje de las virtudes para estudiar los procesos de justificación del conocimiento válido ( $c f r$. ZAGZEBSKI, 1996: 6 y ss.). 
de positivismo deambula en los pasillos tribunalicios, y en las cátedras universitarias, susurrando voces que sólo pertenecen a un pasado superado.

Esto no se debe sólo a datos del presente como aquéllos sobre los que han llamado la atención iusfilósofos de la escuela alicantina como ATIENZA-RUIZ MANERO (2007: 7-28), en el sentido de señalar la existencia evidente de la incorporación de moralidad sustantiva a nuestros ordenamientos constitucionales o a la falta de autonomía semántica de una legión de términos jurídicos como «trato infamante», «pena cruel», «buen padre de familia», «precio justo», etc. A este señalamiento se le puede replicar que estos datos son «contingentes» para el positivismo metodológico, y admitidos por el «soft or inclusive legal positivism» a título de fuentes que deberían ser tenidas en cuenta sólo si han sido incorporadas al derecho de manera efectiva (GREEN, 2003). Empero, en mi opinión, estos datos son engañosamente o superficialmente «contingentes». Como HABERMAS (2010), o antes HegEl han mostrado, la modernidad progresivamente va incorporando elementos morales que evidencian una conexión conceptualmente necesaria entre derecho y moral. El Estado de derecho, diría HEGEL, es ya la encarnación de una comunidad ética de vida (BRUDNER, 2004).

Si suavizamos la afirmación universalista hegeliana sólo para los estados constitucionales de derecho, podemos usar un cuantificador heterodoxo del estilo «para la mayoría» de los ordenamientos jurídicos, la moralidad es un test que interviene tanto en la identificación de validez de las reglas, como en el examen de su virtual aplicación a casos concretos 9 . Ergo, no es cierto que la moralidad sea un dato puramente contingente. Pero esto por dos razones de peso adicionales. La primera es que no creo que la moralidad del derecho se pueda explicar de manera autorreferente con éxito ${ }^{10}$. La autorreferencia conlleva la paradoja de que requiere de otras reglas, extendidas hasta el infinito, para dar cuenta de la moralidad del derecho (NiNO, 1997: 43-44). Pero además, tratar de explicar lo jurídico sólo a partir de lo jurídico como han intentado teóricos sistémicos como LUHMANN arrastra el riesgo de cegarnos frente a la evidencia aplastante de los datos morales que consigné más arriba ${ }^{11}$. Además, pretender tal cosa

9 Además soy de la opinión de que el análisis filosófico no necesariamente pierde identidad si deja de lado conexiones conceptuales necesarias a priori y avanza sobre conexiones conceptuales a posteriori, pero no por ello meramente episódicas o rapsódicas.

10 Teubner (2011: 376) ha mostrado algunos de los inconvenientes de la autorreferencia jurídica, básicamente en el sentido de que la misma es reluctante a las «buenas razones» que trascienden el nivel literal de los textos jurídicos, citando un célebre párrafo del Talmud que transcribo textualmente aquí: «The Talmud tells us how once during a beated halachic discussion, when no agreement could be reached, Rabbi Eliezer, whose detailed, elegantly justified legal opinion was not shared by the majority, said that if he were right, a carob tree outside would move to prove it. When it did move, the other rabbis remained unimpressed. Eliezer claimed that if be were right, a nearby stream would flow backwards —and it did; be claimed that the schoolhouse walls would bend-and they did. But the rabbis were not impressed by these wonders either. Finally be said beaven itself would prove him right. Thereupon a Heavenly Voice confirmed Eliezer's position. Yet the rabbis disagreed even with this voice, saying: "We pay no attention to a Heavenly Voice, because Thou hast long since written in the Torah at Mount Sinai, after the majority must one incline". And God laughed, saying "My sons have defeated Me, My sons have defeated $M e^{\prime \prime} \gg$.

11 La moralidad del derecho, a mi juicio, tiene un carácter «bifronte». Por una parte alude a estándares explícitos o implícitos que existen en el derecho bajo una etiqueta que bien podría llamarse, lo que L. FULLER denominaba la «moralidad interna del derecho». Aquí podríamos incluir principios como el del origen democrático del poder, imperio de la ley, certeza y previsibilidad jurídicas, irretroactividad general de la ley, o aquellos valores o razones de estirpe originariamente moral que impregnan estándares legales, principios constitucionales o, sencillamente, predicados axiológicos que forma parte de los ordenamientos jurídicos. Este 
es como intentar salir del pozo tirando hacia arriba de la propia cabellera. En tanto la legitimidad, autoridad o moralidad del derecho tienen una dimensión categorial que trasciende el ámbito jurídico, cada vez que queramos dar cuenta de estos predicados (moralidad, autoridad, etc.) tendremos por fuerza que salirnos, carnapianamente hablando, del «marco» del positivismo ${ }^{12}$. Sencillamente éste no puede dar respuesta a

tipo de moralidad interna integra lo que en otro trabajo (LARIGUET, 2007: 51-78) he llamado la «respuesta jurídica compleja». Esta respuesta es «jurídica» pues se apoya en argumentos, principios o cláusulas interpretativas que la comunidad jurídica reconoce como parte explícita o implícita del derecho. Es «compleja» porque postula que la solución a los problemas normativos no se halla confinada en un sector departamentalizado del derecho sino que puede obtenerse de una inspección más amplia de diversos sectores del derecho. Además es una respuesta que apela a las razones profundas de las normas jurídicas, razones de tipo moral. Pero esta moralidad interna o respuesta jurídica compleja es «conservatista», pues busca preservar la práctica o imagen del derecho en su mejor aspecto. Sin embargo, esta reconstrucción podría todavía ser sometida a un escrutinio moral externo al derecho y que, por tanto, apoyara la necesidad de modificar parcial o totalmente una práctica jurídica. Sin caer en el simplismo analítico de pensar que un derecho inmoral no es derecho, se podría pensar que un derecho inmoral, aun si convenimos en llamarlo «derecho», por mor de una amplitud de las convenciones lingüísticas, ello no eliminaría el dato de que tal derecho «no tiene fuerza necesaria para justificar una decisión práctica de un juez». Para esto necesitaríamos echar mano del otro sentido de la «moral» que tengo en mente, aquel que refiere a lo que podríamos denominar una moralidad «madura», «crítica» o «reflexiva»; moralidad que, como digo, es «externa» al derecho pero a la cual el derecho se haya vinculado por participar del discurso moral general. Llamo «discurso moral general» al entramado de razones, teorías normativas y conceptos morales densos o ligeros que son susceptibles de ser dotados de contenido proposicional y pueden ser articulados en el razonamiento práctico y deliberación moral de individuos. De todas maneras, la participación del derecho en lo que llamo el discurso moral podría sugerir una idea que no suscribo: la superfluidad o irrelevancia del derecho. No. La participación del derecho en la moral es servicial al presupuesto del discurso moral según el cual necesitamos un orden jurídico institucional (E. GUISÁn, 2008: 161-162) que efectivice valores como la coordinación social, establezca condiciones para la paz o posibilite el desarrollo de múltiples fines sociales o individuales que los ciudadanos se proponen. Sin en el brazo del derecho la moralidad sola no podría efectivizar estos fines pues le faltarían los brazos institucionales (legisladores, jueces, etc.) que hagan efectiva la tutela de dichos bienes y, además, tengan la capacidad de resolver autoritativamente conflictos sociales. Aquí es donde resulta crucial dar cuenta de la exigencia de moralidad de los brazos de aplicación de la ley (los jueces). Si estos no son virtuosos, estamos ante un posible fracaso del derecho para concretarse de manera justa en casos concretos donde estén en conflicto ciertas pretensiones.

${ }_{12}$ Un intento sofisticado ha sido ofrecido por J. RAZ (por ejemplo, 2006: 141-175) con su idea de la autoridad como «servicio» (para un análisis meticuloso de la teoría raziana —y su comparación con la propuesta de ALEXY — véase GAIDO, 2011). Según esta concepción, en la identificación del «concepto» de derecho hay un componente moral que tiene que ver con que la autoridad es legítima en tanto recoge las mejores razones para gobernar nuestra conducta. Siendo así, sus razones son «excluyentes» y «perentorias» de nuestro balance ordinario de razones. RAZ va más lejos todavía al escindir analíticamente la etapa de identificación del derecho a nivel abstracto con su reconocido componente moral —instilado por el concepto de autoridad como servicioy la etapa de identificación de normas aplicables a un caso concreto. Aquí el positivista es «excluyente» en tanto sólo apela a pruebas empíricas neutrales para determinar las normas jurídicas aplicables a un caso concreto. Sin embargo, este rasgo excluyente de su positivismo es precario o inestable por cuanto admite que la «equidad» (RAZ, 1998: 1-20) puede jugar un papel revisor de la aplicación de normas jurídicas a un caso concreto. Frente a esta sumaria presentación del pensamiento raziano se abre un racimo de problemas. El primero es que no estoy seguro de que la distinción entre una etapa de identificación «in abstracto» (con la puesta en evidencia de un componente moral en el derecho) y la etapa de aplicación de normas jurídicas (donde habría un test de identificación cerrado a consideraciones morales o políticas extrajurídicas) pueda trazarse de manera irrestricta y tajante. Participo del motto del pragmatismo filosófico según el cual los conceptos reivindican siempre instancias de aplicación concretas. Para el pragmatista, pero antes para KANT o LEIBNIZ, lo que vale en teoría vale en la práctica, esto es, lo que vale en abstracto vale en concreto. No hay separación tajante, en esta versión, entre la identificación in abstracto y una fase aplicativa. Esto resulta una distinción analítica artificial de dudosa sensibilidad práctica. El segundo problema es que abrir la puerta a consideraciones de equidad difícilmente preserve el rasgo «excluyente» del positivismo jurídico. La equidad es un juicio que re-abre el examen de las razones jurídicas a otras razones morales sustantivas que pueden derrotar las consecuencias previstas por las normas o reglas jurídicas. El tercer problema, en mi opinión, es que el concepto de autoridad, como concepto normativo, que tiene linaje político-moral sustantivo y, que en consecuencia, forma parte de la filosofía práctica 
esta cuestión (Delgado PinTo, 1996: 425-440). No está en su espíritu darla. Y creer lo contrario ha traído más confusión que claridad (NAVARRO, 2001: 136).

\subsection{El papel de la frónesis judicial}

Mi embate anterior contra el positivismo jurídico metodológico necesita ser completado, y esto es primordial para mi argumento central, con el dato de las virtudes judiciales. Como señalé, en páginas anteriores, hay cada vez un mayor consenso académico en que nos importa de manera descollante el desempeño moral de los jueces y abogados. A esto se añade el hecho cierto de la proliferación de códigos de ética, la previsión de tribunales de conducta ética y hasta de sanciones legales por faltas éticas. Los códigos de ética no son sólo un reservorio meramente ornamental de reglas. En buena medida, han explicitado las virtudes que los jueces y los abogados deben poseer si es que quieren argumentar de manera racional y aplicar las reglas correctamente. Los jueces viciosos no ofrecen garantía alguna de aplicación racional del derecho. Por ejemplo, y tal como se ha podido apreciar, una argumentación orientada al consenso racional y regimentada por la fuerza del mejor argumento (APOSTEL, 2007: 129-137) no puede ser encarada con éxito por los jueces-avispa de ARISTÓFANES, inclinados a servirse de los argumentos de manera tramposa con el sólo fin de imponer falazmente decisiones inmorales.

Ahora bien, para aplicar reglas en forma correcta, hay que indicar que una de las virtudes judiciales por excelencia es la de la «prudencia» o «frónesis» (LARIGUET, 2013). Para ARISTÓTELES, esta virtud —intelectual— es la responsable nada menos que de la integración armónica de todas las demás virtudes de carácter moral. Es la virtud por antonomasia porque es la que permite el juicio justo y en el momento justo. ARISTÓTELES pensaba que esta virtud ayudaba a discernir, a percibir, los detalles relevantes o «salientes» de un caso particular para poder, así, arribar a la decisión adecuada.

La prudencia es muy relevante por un dato propio de casi todo orden jurídico legislado. Esta clase de órdenes jurídicos utilizan la formulación de reglas o estándares muy abstractos de regulación. Su aplicación, por otra parte, no puede ser reivindicada por la propia regla o estándar. Las reglas y los estándares necesitan ser especificados para el caso concreto o particular (RICHARDSON, 1990: 279-310). Aquí es donde los jueces tienen un poder especialmente convocado para llevar adelante esta tarea de especificación. Según los éticos de la virtud la prudencia es el instrumento adecuado para esta tarea, ya que la misma es un juicio atento a discernir los rasgos sobresalientes de un caso particular. Esta tarea especificatoria podría resultar sencilla cuando el caso parece encajar sin duda alguna bajo la descripción de las reglas o estándares. Pero cuando el caso es relativamente insólito, puede que las reglas se muestren «indeterminadas» al respecto, con lo cual la tarea especificatoria será más creativa y vendrá a completar los espacios indeterminados de las reglas. Aquí el juez tendrá que activar la prudencia para deliberar la forma de decidir si el caso se puede o no incluir bajo la descripción de la

en general y no es patrimonio sólo de juristas, produce una perturbación en la consistencia del positivismo metodológico. Cuando el positivista á la Hart, o á la Raz, emplea el término «autoridad», no es capaz de preservar la coherencia conceptual ni histórica del positivismo, pues introduce un caballo de Troya que lleva a la auto disolución del positivismo. El positivista que mete en su vocabulario teórico el «término» autoridad introduce en el positivismo elementos morales-políticos sustantivos y rompe con la pretendida separación metódica entre «ser» y «deber ser»y con la anhelada neutralidad teórica del filósofo del derecho. 
regla. Sin duda que aquí su tarea será más «creativa» que en los casos sencillos y puede que, en ocasiones, conlleve la necesidad de alterar el derecho de un modo que ya no haga equilibrio con una moralidad subyacente sino que demande una modificación del mismo a la luz de una moralidad externa de tipo crítico.

A este respecto, una discusión perenne en el ámbito jurídico es si en estos casos los jueces ejercitan algún tipo de discreción «fuerte». Supongo que la respuesta que podría dar un ético de la virtud es, en principio, negativa, ya que el juez prudente tendrá la capacidad de articular el derecho con la moralidad de una manera coherente, apelando al equilibrio reflexivo entre el material jurídico disponible y los principios y normas morales que el prudente determine como aplicables al caso particular ${ }^{13}$. La idea sería que la ética de la virtud tiene la capacidad normativa de desplegar un procedimiento heurístico que conduzca a la mejor respuesta que resulte posible para el caso que deba resolver el juez. Si, además, este juez tiene apertura mental, amplitud de miras, coraje, honestidad, humildad, disposición a recibir críticas, a sopesar las ventajas y costos de cada línea de argumentos ${ }^{14}$, a mantenerse sereno, etc., entonces tendrá un «plus» con respecto a los jueces que sólo se constriñen a emplear las técnicas usuales de interpretación y argumentación jurídicas. Un juez virtuoso, además de ser técnicamente competente, es un juez «íntegro». Un juez íntegro es un juez prudente. Y un juez prudente muestra una preciosa armonía en su contextura emocional ${ }^{15}$, poniendo en evidencia el trabajo conjunto de sus virtudes intelectuales y morales.

De todas formas, puede que en otros casos, tal como he señalado anteriormente, los jueces virtuosos encuentren imposible un equilibro entre el derecho interpretado y su moralidad subyacente. Puede que las virtudes, en efecto, los conduzcan a modificar parcialmente el derecho a fin de ajustarlo a parámetros de una moralidad crítica.

Quiero aprovechar el espacio de este trabajo para declarar mi simpatía por la ética de la virtud. Sin embargo, a continuación debo decir que mi simpatía está matizada. Es una simpatía precavida. La simpatía deviene de que creo que las virtudes son instrumentos normativos fecundos para complementar el paisaje teórico sobre el derecho y la argumentación jurídicas. No basta con apelar sólo a las instituciones, necesitamos también tener en cuenta los rasgos de carácter de las personas. Tampoco absolutizan el panorama de la filosofía jurídica y moral los paradigmas deontológico y teleológico. Frente al excesivo rigorismo - de origen kantiano- del paradigma deontológico, la ética de la virtud es sensible a los desafíos del contexto particular de un caso; desafío

13 Esta articulación, empero, es compleja. En el caso de lo que, más adelante, denominaré la «respuesta jurídica compleja», el juez virtuoso buscaría la mejor versión moral inmanente al derecho y, por tanto, su reconstrucción aplicativa sería conservatista del derecho bajo su mejor aspecto. Sin embargo, si el material normativo fuera un obstáculo para esta tarea de equilibrio reflexivo, pues no es factible articular una moral inmanente que presente al derecho bajo su mejor versión, el juez virtuoso tendría que tener el coraje de explicitar una respuesta moral por fuera del derecho. Esto puede suponer que el juez, después de todo, no pueda ser deferente con todos los valores en juego. Su coraje moral podría llevarlo a apartarse de la letra de la ley.

14 A. AmaYa (2011: 135-142), al analizar la concepción de la argumentación judicial reconstruida por M. ATIENZA, muestra la conexión entre un carácter virtuoso y una capacidad incrementada de argumentación racional.

15 Para los éticos de la virtud las emociones son vehículos cognitivos para dar buenas respuestas a problemas normativos. En el fondo, un teórico de la virtud ofrece una ética de las emociones o pasiones. Una educación de las pasiones en términos de respuestas virtuosas, enhebra emocionalidad y racionalidad práctica de un modo estrecho. 
recogido mediante la lente de la prudencia. Por otra parte, el teleologismo utilitarista, particularmente del utilitarismo del «acto», ha sido comúnmente atacado por dejar abierta la puerta al sacrificio de un individuo en aras del bienestar colectivo. Frente a esto, la ética de la virtud postula la existencia de ciertos actos que son nítidamente viciosos y, por tanto, moralmente censurables.

La precaución con que matizo mi simpatía deviene, empero, de que no defiendo a ultranza las bondades de la ética de la virtud. Tengo una mirada abierta a los posibles problemas que esta ética debe enfrentar o dar respuesta satisfactoria. Los filósofos hemos señalado problemas diversos. Por ejemplo referidos a la presunta estrechez original que tenía la «clase de los virtuosos» en la formulación aristotélica que dejaba fuera a jóvenes y mujeres. Otro problema es el de la «educación» de la virtud. Las virtudes no son propiedades heredables de padres a hijos, como sí lo son ciertos rasgos genéticos, lo cual explicaría por qué los hijos de Pericles, a diferencia de su padre, no eran virtuosos. Por tanto, hay que educar en las virtudes. Una manera de hacerlo es salirse del enclaustramiento en el derecho y mirar otras áreas humanísticas como la literatura. Creo que este tipo de problemas que señalo, son fácilmente contestables por la ética de la virtud contemporánea. Porque, por una parte, la clase de los virtuosos ya no tiene la estrechez conceptual que tenía en el pensamiento original aristotélico. La educación jurídica, por otra parte, puede ser reorientada de modo tal que logre estimular las virtudes en los jueces. A menudo se ha pensado, erróneamente, que la ética de la virtud es sólo el envoltorio de una mera «psicología moral» y no forma parte de la ética. Creo que esto es una manera moderna de ver distorsionadamente la ética aristotélica y la ética antigua en general. En la filosofía moral antigua, pienso en los epicúreos y estoicos, y no sólo en los aristotélicos, la ética es en parte psicología y en parte ética normativa. No son hemisferios sin conexión. La ética es psicológica en tanto se preocupa por diagnosticar y reajustar emociones y creencias inadecuadas, y es normativa en tanto se trata de una terapia que expone un catálogo de rasgos de carácter que nos pueden llevar a la excelencia moral, al florecimiento integral o eudaimonía.

Lo que sí creo que comporta un problema para la ética de la virtud, mas no un impedimento absoluto, es el problema del conflicto entre virtudes. En efecto, en los casos en que un agente moral, o un juez, experimente «dilemas morales», «conflictos de conciencia» es casi seguro que las virtudes estarán también en conflicto ${ }^{16}$. La

${ }_{16}$ Cuando se producen colisiones, entre exigencias contrapuestas, bajo la forma de dilemas que los jueces tienen que resolver, podemos enfrentarnos a un problema de conflicto entre dos tipos de moralidades diferentes. Una, la interna, de tipo institucional y ligada a normas y principios jurídicos, y otra externa que puede servir como reserva crítica de la moral en el primer sentido. Pues bien, frente al conflicto entre exigencias contrapuestas, es donde podría entrar en escena la ética de las virtudes. En este sentido, la prudencia, dado que es una virtud «estrella» parece que, prima facie, siempre remitiría a la moral en el primer sentido o en el segundo sentido cuando el primero se halla agotado y ha resultado frustrado por una crítica externa al derecho. En este último sentido, ya el equilibrio reflexivo no se podría mantener con un derecho intacto meramente especificado sino que se buscaría su transformación alumbrada por una moralidad en sentido externo. El juez virtuoso está preparado para este momento difícil pues sabe que hay una pluralidad de valores en conflicto y que no siempre podrá hacerles justicia a todos a la vez. Ahora bien, si justamente somos pluralistas en materia de valores, es decir, si suscribimos la idea de que hay valores diferentes que pueden entrar en conflicto y, si además, somos pluralistas en materia de razonamiento práctico, podríamos presenciar que no hay algo así como un solo tipo de reglas o dimensiones que siempre triunfen sobre las otras, tal como sostendría el «monismo» de valores. Despojando a la prudencia de su tendencia a priorizar siempre una lectura moral (sea en el sentido uno, sea en el sentido dos), esta virtud podría ser reinterpretada, sosteniendo que una sensibilidad por el dato del «value 
pretensión de la virtud, sin embargo, es que la «prudencia» juega un rol estelar como cohesiva de las virtudes en conflicto.

Ahora bien, aun si esta tesis puede ser cierta para muchos casos, no necesariamente es aplicable a todos los casos del mundo. Por ejemplo, en los llamados «casos trágicos», que son aquellos donde haga lo que haga un agente no podrá evitar un mal resultado, es por lo menos incierto si la prudencia puede garantizar la armonía entre virtudes y determinar una respuesta «correcta» para el caso trágico. Pero sí que puede defenderse que si el juez es virtuoso, hará lo mejor posible y vivirá con angustia su decisión, siendo consciente de que, quizá, no pudo evitar completamente sacrificar una opción valiosa. Esta angustia, puede a posteriori, ser el motor para impulsar cambios en el derecho o cambios institucionales que permitan reacomodar las cosas para evitar futuros sacrificios de determinado valor que se juzga importante.

Con independencia de lo anterior, quiero volver al punto de inicio de este trabajo. La idea era que el derecho en la literatura puede ofrecernos un catálogo de ejemplares virtuosos o viciosos que nos resulte útil para contrastar y comparar el desempeño de los jueces literarios con el desempeño de los jueces de carne y hueso. Como ha mostrado Nussbaum (1997) estos jueces tienen mayor sensibilidad y profundidad interpretativa para aplicar el derecho si se comportan como jueces poetas, que si lo hacen como jueces utilitaristas como el señor Gradgring de Tiempos Difíciles de Dickens. Otra manera de educar, por cierto, es recurriendo a la imitación de jueces excelentes (en lo que A. AmaYa llama la teoría centrada en los «agentes). Y, por último, otra forma es centrándose en «casos» resueltos de manera excelente.

\section{CONCLUSIONES}

En este trabajo me he concentrado en una específica manifestación del derecho en la literatura. He basado mi análisis filosófico principalmente en Las avispas de ARISTÓFANES, con ocasionales referencias también a Las nubes, texto del mismo autor.

pluralism» (LARIGUET, 2011c: 161-184) podría conducir eventualmente a otros resultados donde la moral, en ninguno de los sentidos anteriores, resulte privilegiada. Desde este punto de vista se podría considerar que la prudencia no necesariamente remitiría siempre a un criterio moral pues, quizá, y bajo la cláusula de que admitamos el pluralismo de valores, la misma podría aconsejar el razonable predominio de valores políticos e inclusive estéticos por sobre los valores morales externos o internos al derecho. Esto sin duda podría sonar contra intuitivo para una lectura lineal de la ética de la virtud y también para aquellos que presuponen un lugar central para el derecho o para la moral, argumentando que son valores entre valores. Pero si uno admite, por hipótesis, el pluralismo, a lo mejor, estaría justificado a dudar de que esta primacía de la moral o el derecho se mantenga siempre intacta. La pregunta, con todo, más allá de qué interpretación de la prudencia consignemos, seguirá siendo si la prudencia siempre garantizará una salida airosa de todos los dilemas que se le planteen a los jueces. $\mathrm{Y}$ en conexión con esta pregunta, la otra sería si, no obstante admitir el pluralismo de valores, estaríamos dispuestos a sostener que existan ciertos meta criterios para resolver conflictos entre dominios diferentes. Me inclinaría a hipotetizar que, quizá, si estos metacriterios existiesen nos empujarían, en general, a dotar de primacía a los valores morales por sobre otra clase de valores. De este modo, a lo mejor, la unidad del razonamiento práctico siga siendo la regla, mientras que un pluralismo razonable quedaría como estrategia residual para ciertos casos donde resulte aceptable que otros valores no-morales triunfen sobre los morales. En cualquier caso, la cuestión de cómo estructurar el razonamiento práctico, si como unitario - a nivel de regla general — y pluralista — a nivel residual—, es un tema que exige una meditación más extendida en el tiempo y, por fuerza analítica, una articulación conceptual más detallada. Por otra parte, la tarea de «encontrar»o «inventar» metacriterios de resolución de conflictos entre valores pertenecientes a distintos dominios, me parece una pesquisa abierta todavía y, por tanto, pendiente de muchas más cavilaciones. 
He sostenido que la lectura de estos textos literarios nos permite reexaminar el importante problema de la moralidad de los jueces. La obra de la comedia griega analizada opera como un «aguijón» frente al duermevela de los juristas que no prestan atención al impacto que ciertos vicios pueden tener en la adopción de decisiones inmorales o que quepa considerar como injustas. Este aguijón aristofanesco no es el mismo aguijón «semántico» con el que DwORKIN criticaba al positivismo de tipo hartiano. Este es un aguijón moralista porque ofrece, mediante el recurso a la risa, argumentos críticos dirigidos contra los vicios que los jueces deberían extirpar si es que quieren convertirse en buenos jueces.

He combinado el cuadro literario de ARISTÓFANES con la propuesta normativa de la ética de la virtud. He sostenido que la atención en las personas virtuosas es un modo de complementar aquellos análisis sólo centrados en el diseño de instituciones justas. La importancia de las personas y no sólo de las instituciones ya fue entrevista por RAWLS cuando imputaba a los agentes morales de su teoría un «sentido de la justicia». La justicia como sentido es una virtud, tal como ya sostenía ARISTÓTELES. Desde luego, y esto lo admito, además del discurso de las virtudes, requerimos de buenas teorías normativas en el ámbito político y moral que nos revelen las condiciones intersubjetivas que una sociedad bien ordenada debe satisfacer para tener instituciones justas. Pero, repito, hay que complementar las instituciones justas con las personas virtuosas dotadas de una sensibilidad por la justicia.

He afirmado que la preocupación extendida y masiva por la moralidad de los jueces, atestiguada por los códigos de ética, los tribunales de ética, las reuniones académicas y de foros de abogados y jueces encaminadas a sentar bases para una ética forense, etc., sugiere que la relación entre moral y derecho es mucho más estrecha de lo que el positivismo metodológico supone. No basta con centrarse en el dato de reglas saturadas de connotaciones morales. También hay que prestar atención a la necesidad de que los funcionarios de un sistema jurídico sean morales. He argüido que «ser moral» no tiene porqué explicarse sólo con el recurso a los paradigmas dentológicos o teleológicos. La moralidad de los jueces parece estrechamente ligada con el discurso de las virtudes. Aunque me he ocupado en este trabajo primordialmente de los jueces, soy de la creencia de que la ética de la virtud puede extenderse con provecho para forjar las condiciones para evaluar a legisladores y ciudadanos virtuosos y no quedar confinada, solamente, a los jueces que aplican las reglas. Necesitamos legisladores que sepan discernir adecuadamente qué reglas necesitamos y a ciudadanos que desplieguen lo que los republicanistas llaman «virtudes republicanas».

He señalado antes el fracaso del positivismo metodológico, es decir el que separa conceptualmente derecho respecto de moral, para dar cuenta, en cambio, la existencia de vinculación fuerte del derecho con la moral ${ }^{17}$. Esta vinculación no sólo se da en el plano de las «instituciones jurídicas» sino también de las «personas de carne y hueso» que encarnan estas instituciones. Es posible que a veces los jueces sean «inmorales», pero precisamente en este reconocimiento está cifrada nuestra expectativa normativa

17 «Fuerte» en el sentido de que un derecho que se desvincula de la preocupación por un contenido moral o justo tiene una muy amenguada fuerza para apoyar la justificación de decisiones prácticas. Frente a este inconveniente es que nuestra expectativa normativa es que los jueces sean virtuosos y dotados de capacidad de enmendar fallas de moralidad o justicia. 
de que ellos deben ser «morales», en el sentido de «virtuosos». La idea es que un juez virtuoso está más capacitado que un juez puramente «técnico» para buscar la solución justa para un caso.

Frente a los datos que he mencionado antes, sostener que la vinculación es contingente es inadecuado y superficial. Pues no es contingente la expectativa de que los jueces sean virtuosos. A esto se le suma un dato no contingente y es la incapacidad conceptual del propio positivismo metodológico para responder sobre la vinculación del derecho con la moral. Frente a esto, coincidiría con D. PRIEL (2011:1-35) en que las relaciones entre validez, contenido, normatividad y legitimidad son muy fuertes en un modo que es distorsionado por el tipo de distinción analítica que trazan los positivistas estándares entre estos conceptos. La idea dworkiniana de que hay que explicar las relaciones holísticas entre estos conceptos demanda un tipo de filosofía del derecho no endogámica, no cerrada en sus pequeñas fronteras. Demanda una filosofía del derecho que utilice el aparato normativo ${ }^{18}$ de las teorías elaboradas por los filósofos políticos y morales. Esto no tiene por qué desdibujar la identidad o autonomía disciplinar relativa de la filosofía del derecho. Lo que señala, más bien, es que si queremos ser buenos filósofos del derecho, tenemos que esforzarnos por ser también buenos filósofos morales y políticos.

\section{BIBLIOGRAFÍA}

Aguiló, J., 2009: «Dos concepciones de la ética judicial», Doxa, Cuadernos de Filosofía del Derecho, núm. 32.

AmaYA, A., 2011: «Virtudes, argumentación jurídica y ética judicial», Diánoia, vol. LVI, núm. 67, México: Instituto de Investigaciones Filosóficas, UNAM.

- 2012: «Derecho y Literatura», en SCRN, http://papers.ssrn.com/sol3/papers.cfm?abstract_ $i d=2064297$.

— 2013: «Exemplarism and Judicial Virtue», MS inédito cedido por gentileza de la autora.

AmaYa, A., y Hock LaI, H., 2012: Virtues, law and justice, Oxford: Hart Publishing.

ANDERSON CAMACHO, F., 2007: «Los jueces y abogados frente a la literatura universal», en D. Cienfuegos Salgado y M. ${ }^{a}$ C. Macías Vázquez (coords.), Estudios en homenaje de Marcia Muñoz de Alba Medrano, La enseñanza del derecho, UNAM, Instituto de Investigaciones Jurídicas, 67-85.

Apostel, L., 2007: «¿Cuál es la fuerza de un argumento? Algunos problemas y sugerencias», J. Trujillo Amaya (trad.), Praxis Filosófica, Cali: Universidad del Valle, 129-138.

Aristófanes, 2011a: Avispas, L. BALZARETTI y M. Coria (introducción, trad. y notas), Buenos Aires: Losada.

18 Por supuesto, habría que ver qué lugar le daremos a elementos explicativos de tipo empírico como los que tienen que ver con, por ejemplo, el ejercicio fáctico del poder político o, para el caso de los jueces, una sociología jurídica que explique cómo operan habitualmente los jueces en cierto tipo de casos. Una teoría normativa podría, desde luego, entrar en tensión con datos explicativos. Esto tiene que ver, en última instancia, con la presencia de argumentos «realistas» (para el caso de los datos empíricos o explicativos) y morales (en el sentido de normativos) en la política y, por extensión, podríamos añadir, en el derecho. Puede que, en efecto, tengamos un hiato que superar entre el normativismo de ciertas filosofías jurídicas (por caso de la filosofía aretaica) y el naturalismo de teorías jurídicas más empíricas o centradas en la explicación de aspectos empíricos o causales en torno al derecho. 
- 2011b: Las nubes, F. BarÁibar (trad. y noticia preliminar), P. EnRíquez UreÑa (introducción y notas), Buenos Aires: Losada.

Aristóteles, 1974: Poética, V. García Yebra (trad.), Madrid: Gredos.

ATIENZA, M., 2001: «Virtudes judiciales. Sobre la formación y selección de los jueces en el Estado de derecho», en M. ATIENZA, Cuestiones judiciales, México: Fontamara.

AtienzA, M., y Ruiz MAnERo, J., 2007: «Dejemos atrás el positivismo jurídico», Isonomía. Revista de teoría del derecho, núm. 27, México, 7-27.

BONNER, R., y SCHMith, G., 2000: The administration of justice from Homer to Aristotle, Union, NJ: Exchange.

BORDES SOlAnAS, M., 2011: Las trampas de Circe: Falacias lógicas y argumentación informal, Madrid: Cátedra.

Boyd White. J., 1985: The legal imagination, Chicago: The Chicago University Press.

BRudNER, A., 2004: Constitutional Goods, Oxford: Oxford University Pres.

BRuner, J., 2003: La fábrica de historias. Derecho, literatura, vida, L. Padilla (trad.), México: Fondo de Cultura Económica.

Buis, E., 2001: «Persuadir, legislar y juzgar en Aves. Apostel y los alcances jurídico-políticos del uso de hipótesis eventuales», Argos (Revista de la Asociación Argentina de Estudios Clásicos), 24 (julio), 7-22.

Delgado Pinto, J., 1996: «Normatividad del derecho», en E. Garzón Valdés y F. LaPORTA (eds.), El derecho y la justicia, Madrid: Trotta, 425-440.

GAIDO, P., 2011: Las pretensiones normativas del derecho. Un análisis de las concepciones de Robert Alexy y Joseph Raz, Madrid: Marcial Pons.

GONZÁLEZ DE LA VEGA, R., 2013: «The paradox of normativity of law. A comment on Veronica Rodríguez-Blanco's solution», Problema. Anuario de filosofía y teoría del derecho, núm. 7 , Instituto de Investigaciones Jurídicas, UNAM, 76.

GREEN, L., 2003: «Legal Positivism», Stanford Encyclopedia of Philosophy, http://plato.stanford. edu/entries/legal-positivism/.

GUISÁN, E., 2008: Razón y pasión en ética. Los dilemas de la ética contemporánea, Madrid: Anthropos, 161-162.

HABERMAS, J., 2010: Facticidad y validez. Sobre el derecho y el estado democrático de derecho en términos de teoría del discurso, M. JIMÉNEZ REDONDO (trad.), Madrid: Trotta.

LARIGUET, G., 2007: «El desafío de Billy Budd. Dilemas morales y dimensión institucional del derecho», Crítica. Revista Hispanoamericana de Filosofía, vol. 39, núm. 116, México, 51-78.

- 2008: Dilemas y Conflictos Trágicos. Una investigación conceptual, M. ATIENZA (prólogo), Lima-Bogotá: Palestra-Temis.

— 2011a: «Las tensiones internas del pluralismo moral», Isegoría, núm. 44, Madrid, 161-184.

- 2011b: Encrucijadas Morales. Una aproximación a los dilemas y su impacto en el razonamiento práctico, R. González de LA Vega (prólogo), Theoria cum Praxi, Madrid: Plaza y Valdés.

- 2012: Virtudes, ética profesional y derecho. Una introducción filosófica, Buenos Aires-Montevideo: $\mathrm{B}$ de F. Editores.

- 2013: «Una introducción general al giro aretaico en la filosofía del derecho contemporánea y su vínculo con los dilemas morales», en R. GONZÁLEZ DE LA VeGA y G. LARIGUET (eds.), Problemas de filosofía del derecho. Nuevas perspectivas, Bogotá: Temis, en prensa.

Lariguet, G., y MARTínez, D., 2008: Els dilemes morals, Barcelona: Ediuoc.

Magris, C., 2008: Literatura y derecho. Ante la ley, México, DF: Sexto Piso.

MALEm SeÑA, J., 2001: «Pueden las malas personas ser buenos jueces?», Doxa. Cuadernos de filosofía del derecho, núm. 24, Alicante, 379-403. 
MARí, E.: «Derecho y Literatura. Algo de lo que sí se puede hablar pero en voz baja», Doxa. Cuadernos de Filosofía del Derecho, núm. 21, vol. 2, Alicante, 251-287.

Morawetz, T., 1996: «Law and Literature», en D. Patterson (comp.), A Companion to the Philosophy of Law and Legal Theory, Malden: Blackwell, 450-461.

NAVArRo, P., 2001: «Tensiones conceptuales en el positivismo jurídico», Doxa. Cuadernos de Filosofía del Derecho, Alicante, 136.

NinO, C., 1997: La Constitución de la Democracia Deliberativa, Barcelona: Gedisa, 43-44.

Nussbaum, M., 1997: Poetic Justice: the literary imagination and public life, Boston-Massachusetts: Beacon Press.

Ost, F., 2006: «El reflejo del derecho en la literatura», Doxa. Cuadernos de Filosofía del Derecho, núm. 29, Alicante, 333.

Posner, R., 1998: Law and literature, Harvard: Harvard University Press.

PRIEL, D., 2011: «The place of legitimacy in legal theory», McGill Law Journal, 1-35.

RAZ, J., 1998: «Postema on Law's Autonomy and Public Practical Reasons: A Critical Comment», Legal Theory, 4, 1-20.

- 2006: «El problema de la autoridad. De nuevo sobre la concepción de la autoridad como servicio», P. Gaido (trad.), Doxa. Cuadernos de Filosofía del Derecho, núm. 29, Alicante, 141-175.

RICHARDSON, H., 1990: «Specification as a way to resolve concrete ethical problems», Philosophy and Public Affairs, 279-310.

SALAS, M., 2007: «¿Es el derecho una profesión inmoral?. Un entremés para los cultores de la ética y de la deontología jurídica», Doxa. Cuadernos de Filosofía del Derecho, núm. 30, Alicante, 581-600.

SCAfuro, A., 1997: The forensic stage: Setting disputes in Graeco Roman new comedy, Cambridge: Cambridge Universiy Press.

Sen, A., 2011: La idea de justicia, H. Valencia Villa (trad.), Buenos Aires: Taurus, 105-116.

SILK, M., 2001: Aristophanes and the definition of comedy, Oxford: Oxford University Press.

Teubner, G., 2011: «And God Laughed...: Indeterminacy, Self-Reference and Paradox in Law», German Law Journal, 12, 376.

Williams, B., 2011: «La filosofía como disciplina humanística», en B. Williams, La filosofía como disciplina humanística, A. W. MoOre (sel., coord. e intr.), A. GARCía DE LA SiENRA (trad.), México DF: FCE, 202-221.

- 2012: El sentido del pasado. Ensayos de bistoria de la filosofía, M. BuRnYEAT (ed. e intr.), P. Williams (pref.), A. GARCía DE LA SiEnRA (trad.), México DF: FCE.

ZAGZEBSKI, L., 1996: Virtues of the Mind. An inquiry into the nature of virtue and the ethical foundations of knowledge, Cambridge: Cambridge University Press. 